\title{
Primer total diz artroplastisinde hastalığa özgü komplikasyonlar
}

\author{
Disease specific complications in primary total knee arthroplasty
}

\author{
Erdi Özdemir, Ömür Çağlar
}

Hacettepe Universitesi Tıp Fakültesi, Ortopedi ve Travmatoloji Anabilim Dalı, Ankara

\begin{abstract}
Primer osteoartrit dışı endikasyonlarla uygulanan total diz artroplastisi sayısı giderek artmaktadır. Bu hastalıklar içinde romatoid artrit, hemofilik artropati, yüksek tibial osteotomi sonrası ve nöropatik artropatiye bağlı total diz protezi uygulamaları sayılabilir. Bu hastaların ortopedik problemlerine ek sistemik problemleri olduğu ve bu problemlerin cerrahi sonuçları etkileyebileceği unutulmamalıdır. Bu hastaların tıbbi durumları ameliyat sonrası komplikasyonlarla doğrudan ilgilidir. Primer osteoartrit dışı hastaların primer total diz protezinde farklı komplikasyonlar görülebilir. Hastalıklara özgü komplikasyonların bilinmesi, cerrahları bu komplikasyonları azaltma ve cerrahi başarısını yükseltme konusunda yardım edecektir. Bu derleme yazısında, primer osteoartrit dışı durumlarda uygulanan total diz artroplastilerinde görülen hastalığa özgü komplikasyonlar tartışılacaktır.
\end{abstract}

Anahtar sözcükler: komplikasyon; hastalığa özgü; sekonder osteoartrit

\begin{abstract}
The number of total knee arthroplasties performed for diseases other than primary osteoarthritis are increasing. These patients are operated for total knee replacement mostly secondary to rheumatoid arthritis, hemophilic arthropathy, failed high tibial osteotomy and neuropathic arthropathy. It should be kept in mind that these patients may have significant medical problems additional to their orthopedic disease and these problems may affect the surgical outcomes. Their medical status closely affects the complication rate after surgery. Some different complications could be observed after the operation for non-primary osteoarthritis. Being aware of disease specific complications helps in reducing complication rate and improving outcomes. In this review, disease specific complications of primary total knee arthroplasties for non-primary osteoarthritis will be discussed.
\end{abstract}

Key words: complication; disease specific; secondary osteoarthritis

sıklıklarının bilinmesi; hasta seçimi, kullanılacak cerrahi teknik, seçilecek implant, hasta güvenliği ve fonksiyonel sonuçlar açısından önem arz etmektedir.

Bu makalede, primer osteoartit dışı nedenlerle yapılan primer total diz protezlerinde görülebilecek komplikasyonlar ve literatürdeki olgu serileri tartışılacaktır.

\section{ROMATOID ARTRIT HASTALARINDA GÖRÜLEN KOMPLIKASYONLAR}

Dizin inflamatuvar artrit patogenezi, medikal tedavi, prognoz ve beklenen sonuçları açısından osteoartritten farklılık gösterir. Romatoid artrit inflamatuvar artritler arasında en sık görülendir. Romatoid artrit, otoimmün sinovit zemininde kıkırdak harabiyeti ile sonuçlanan bir hastalıktır. İleri evre romatoid artrit hastalarında diz eklemi \%90'a varan oranlarla etkilenir. ${ }^{[2]}$ Primer TDA uygulanan hastaların \%8'lik bir bölümünü

- Illetişim adresi: Doç. Dr. Ömür Çağlar, Hacettepe Üniversitesi Tıp Fakültesi, Ortopedi ve Travmatoloji Anabilim Dalı, Sıhhiye, 06100, Ankara, Türkiye Tel: 0312 - 3051209 e-posta: omurcaglar@hotmail.com

- Geliș tarihi: 19 Aralık 2018 Kabul tarihi: 19 Aralık 2018 
romatoid artrit hastaları oluşturmaktadır. ${ }^{[3]}$ Hem hastalığın doğal özellikleri, hem de medikal tedavisinde kullanılan steroid ve immün modülatör ilaçlar; TDA sonrası görülen komplikasyonların sıklığını değiştirir. Bu komplikasyonlar arasında en önemlileri; enfeksiyon, yara yeri problemleri ve periprostetik kırıklar olarak sıralanabilir.

Hastalığın doğal otoimmün karakteri ve tedavisinde kullanılan kortikosteroid, DMARD (hastalığı modifiye eden antiromatizmal ilaçlar) ve TNF- $\alpha$ inhibitörleri gibi ilaçlar, hastaları cerrahi sonrası enfeksiyon gelişimine yatkın hale getirir. ${ }^{[4]}$ Ameliyat dönemi metotreksat kullanımı kısa dönem cerrahi enfeksiyon riskini değiştirmese de, leflunomid ve TNF- $\alpha$ inhibitörleri enfeksiyon riskini arttırırlar. ${ }^{[5]}$ Kronik kortikosteroid kullanan hastalarda, adrenal yetmezlik gelişmesi açısından dikkatli olunmalıdır. Cerrahi işlemden önce stres dozunda steroid uygulanması önerilir. ${ }^{[6]}$ Kortikosteroid kullanan hastalar 1,5-4 kat daha çok enfeksiyon riski taşırlar. Bu nedenle, cerrahi sırasında sterilitenin sağlanması konusundan daha fazla çaba gösterilmelidir. ${ }^{[3]} \mathrm{Bu}$ hastalarda ameliyat öncesinde verilen ilaçlar kesilse de, çoğunlukla ameliyat sonrasında erken dönemde yeniden başlanacaktır. Primer osteoartrit hastalarında yapılan primer diz artroplastisi sonrasında ilk beş yıl içinde görülen enfeksiyon oranı romatoid hastalarına göre yaklaşık beş kat fazladır. Romatoid artrit hastalarında anemi görülmesi ihtimali yüksektir. Bu hastaların anemilerinin cerrahi öncesi düzeltilmesi, hastaların kan transfüzyonu ihtiyacını azaltarak enfeksiyon riskini düşürür. ${ }^{[7]}$

Yara yeri iyileşmesi romatoid artrit hastalarında önemli bir sorundur. Hastalığın doğal seyri, immünsupresan ilaç kullanımı ve kortikosteroid kullanımı, bu sorunun başlıca nedenleridir. Metotraksat kullanımının dokuda gerilim kuvvetini azalttığı gösterilmiştir; fakat bu hastalarda kullanılan doz göreceli olarak düşüktür. Cilt ve cilt altı dokusu çoğunlukla atrofiktir ve kolaylıkla travmatize olabilir. ${ }^{[2]}$ Yara yeri kapatılması aşamasında dikkatli olunmalıdır.

Romatoid artrit hastalarında; hastalığın kendi otoimmün doğası ve kronik steroid kullanımı sonrasında kemik kalitesinde bozulma ve osteopeni görülmesi sık rastlanan bir durumdur. Özellikle kuvvetli implant tespiti için gerekli olan iyi subkondral kemik kalitesi bu hastalarda kaybedilebilir. Subkondral kemiğin romatoid tutulumu ile granülasyon dokusu ile yer değiştirmesi ve sinoviyumdan prostoglandin salınımı, kemik kalitesini azaltan faktörlerdir. ${ }^{[2]}$ Kemik içinde belirgin kistlerin oluşması az karşılaşılan bir durum değildir ve büyüklügüne göre, kemik çimentosu veya greftleri ile kemiğin rekonstrükte edilmesi gerekir. Bu da, periprostetik kırık riskinde artmaya neden olur (Şekil 1 ve 2). Bogoch ve Moran, 55 romatoid artrit hastasına uyguladıkları primer TDA serilerinde, 12 hastada 15 yıllık takip sonrası suprakondiller periprostetik kırık rapor etmişlerdir. ${ }^{[8]}$

Derin ven trombozu görülme riski romatoid artrit hastalarında primer osteoartrit hastalarına göre üç kat daha düşük olarak rapor edilmiştir. ${ }^{[9]}$ Buna neden olarak, bu hastaların daha genç yaşta cerrahi geçirmeleri ve kullanılan nonsteroidal anti-inflamatuvar ilaçların (NSAii) antiplatelet etkileri düşünülmektedir.

Literatürde romatoid artritli hastalara uygulanan diz artroplastilerinin fonksiyonel sonuçlarının primer osteoartrite göre daha düşük olduğunu bildiren çalışmalar bulunmaktadır. ${ }^{[10]}$ Fakat, DMARD ve biyolojik ilaçların romatoid artrit tedavisindeki başarılarının yüksek olması dolayısıyla; bu hastalara uygulanan diz artroplastilerinin, ağrı ve fonksiyonel sonuçlar açısından günümüzde primer osteoartritten farkı kalmamıştır. ${ }^{[11]}$

\section{HEMOFILIK ARTROPATI HASTALARINDA GÖRÜLEN KOMPLIKASYONLAR}

Hemofilik artropati tekrar eden hemartrozlar sonrası kronik sinoviyal inflamasyon ile eklem kıkırdağının zarar görmesi sonucu gelişir. Diz eklemi en sık tutulan eklemdir. Hastaların cerrahi öncesi medikal durumları faktör ve inhibitör düzeyleri açısından ortaya konulmalıdır. Hemofili hastaları yaşamları boyunca çok miktarda kan ürünü kullanmaları gerektiğinden HCV ve HIV gibi immün sistemi etkileyen enfeksiyon geçirme ihtimalleri yüksektir. Bu yüzden, hastalara cerrahi öncesi immünite testleri uygulanmalı ve gerek duyulduğu takdirde cerrahileri ertelenmelidir.

Hemofilik artropatiye sekonder TDA sonrası komplikasyonlar erken ve geç dönem olarak gruplandırılabilir. Erken dönem komplikasyonların başında, eklemde şişlik ve hematom gelir. Literatürde hematom sıklığı $\% 2,8-12,5$ arasında değişmektedir. ${ }^{[12]}$ Nadiren cerrahi işlem ile hematom boşaltılması işlemi yapılması gerekebilir. Bir diğer erken dönem komplikasyon da eklemde hareket kısıtlılı̆ıdır. Hastalara genel anestezi altında manipülasyon uygulanabilir. ${ }^{[13]}$ Ameliyat sırasında sıkı bir hemostaz sağlanması ve uygun faktör replasmanı ile hematom oluşması engellenebilir. Bu sayede, hematomun yaratabileceği eklem hareket kısıtlılığının önüne geçilebilir. Ameliyat sonrası dönemde diz hareket açıklığını belirleyen bir diğer durum ise ameliyat öncesi dönemdeki eklem hareket açıkığıdır. Ameliyat öncesi dönemde fleksiyon kontraktürünün ilerlemesini beklemeden diz artroplastisinin uygulanması, ameliyat sonrası fleksiyon kontraktürünün azaltılması ve hareket açıklığının korunabilmesi için önerilir. ${ }^{[14]}$

Cerrahi sonrası dönemde uygun venöz tromboembolizm (VTE) profilaksisi, hemofili hastalarındaki kanama bozukluğu nedeniyle tartışmalı bir durumdur. 


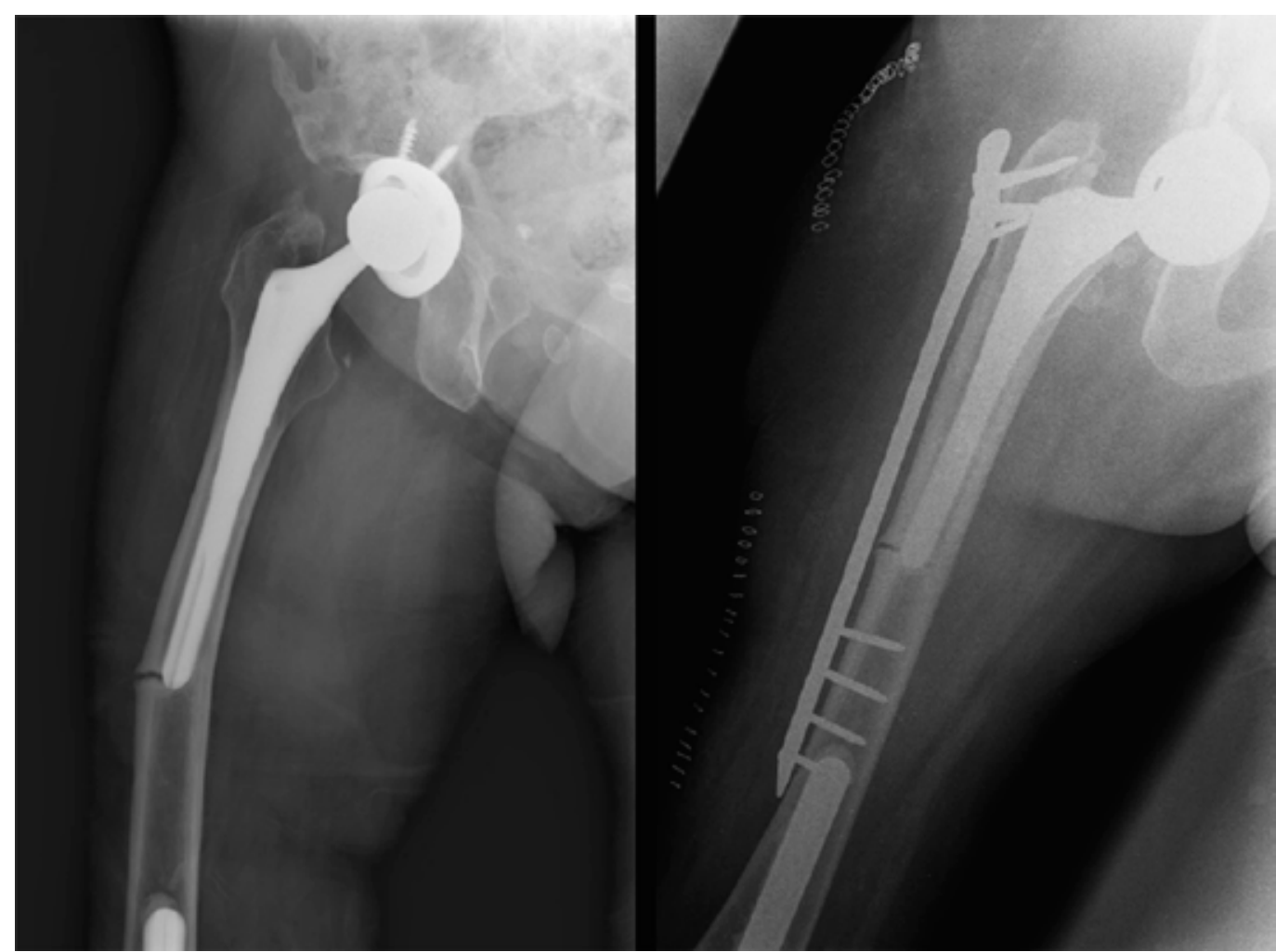

Şekil 1. Yetmiş bir yaşında kadın hastaya, romatoid artrite sekonder, sağ total kalça ve diz artroplastisi uygulanmış. Femoral stemin distalinde gelişen periprostetik kırık, plak ile tespit ediliyor.

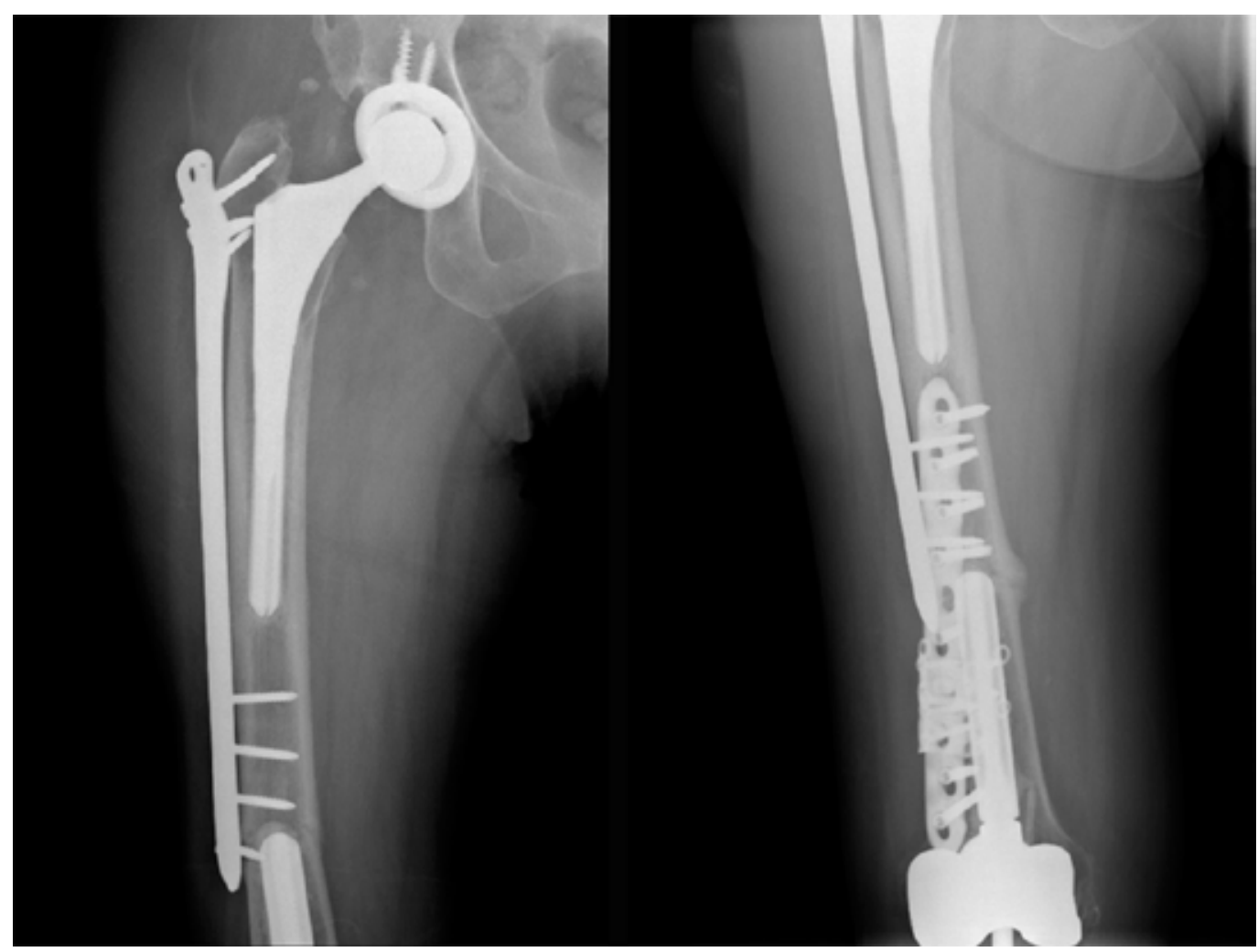

Şekil 2. Aynı hastada altı ay sonra plak distali ve diz artroplastisinin femoral stemi arasından tekrar kırık gelişiyor. Plak ile tespiti sonrası kaynadığı görülüyor. 
Faktör replasmanı sonrası VTE riskinin primer osteoartrit hastalarından daha yüksek olduğu literatürde belirtilmiştir. ${ }^{[15]}$ Browne ve ark.'nın çalışmasına göre, hemofili hastalarında VTE riski \%3,2 olarak rapor edilmiştir ve VTE profilaksisi önerilmektedir. ${ }^{[16]}$

Enfeksiyon, hemofilik artropatili hastalarda artroplastinin en önemli komplikasyonudur; cerrahi sonrası erken dönemde veya daha ileri bir zamanda ortaya çıkabilir. Erken dönemde, primer osteroartritte uygulanan antibiyotik rejimleri ile enfeksiyon riski birbirine benzerdir. Uzun dönem göz önüne alındığında, enfeksiyon oranları \%3,5'e kadar yükselmektedir. ${ }^{[16]}$ Enfeksiyonun kaynağı, çoğu zaman lokal veya vücudun başka bir odağından kaynaklanan bakteriyemidir. Bu risk artışının kesin nedeni belirlenememiş olsa da, hastaların transfüzyon ihtiyacı ve intravenöz faktör replasmanları suçlanmaktadır. Bunun yanında, hastaların transfüzyonları esnasında edindikleri HCV, HIV gibi virüsler enfeksiyon riskini arttıran diğer nedenler arasındadır. Hemofili hastalarında dental manipülasyonlar öncesi enfeksiyon riskini azaltmak amacıyla antibiyotik profilaksisi şiddetle önerilmektedir. ${ }^{[13]}$

Başarılı bir primer TDA sonrası ani başlangıçlı ağrı ve şişlik, hemofili hastalarında görülebilen bir durumdur. Fakat, başarılı bir cerrahi sonrası geç dönemde akut kanama atağı beklenen bir durum değildir. İntravenöz faktör replasmanlarına yanıt alınamaması durumunda, aksi kanıtlanana kadar enfeksiyon ihtimali akıldan çıkarılmamalıdır.

Hemofili hastalarının primer TDA sonrası başarı oranlarının yükseltilmesi ve risklerin azaltılabilmesi için, hastanın kendisi, bu yaşam tarzına uyum göstermelidir. İmmün sisteminin güçlü tutulması, dental hijyenin iyi sağlanması ve herhangi bir enfeksiyon durumunda beklenmeden tedaviye başlanması, uzun dönemde başarı oranını yükseltecektir.

\section{YÜKSEK TIBIIAL OSTEOTOMI SONRASI OSTEOARTRIT}

Yüksek tibial osteotomi, unikompartmantal diz osteoartritinde etkinliği gösterilmiş başarılı bir cerrahi tedavi seçeneğidir. Genç hastalarda uygun endikasyon ve yöntemle uygulandığında, diz ağrısını azaltmakta ve mesleğe dönüşü kolaylaştırmaktadır. Fakat nadir olmayarak, ağrının azaldığı bu dönem bazı hastalarda geçici bir dönemdir. İlerleyen zamanda, yüksek tibial osteotomi sonrası hastalara TDA uygulanması gerekebilir. Literatürde yüksek tibial osteotomi sonrası TDA'nın sonuçlarının primer olgulara göre daha düşük ${ }^{[17]}$ veya benzer ${ }^{[18]}$ fonksiyonel sonuçları olduğunu bildirir karşılaştırmalı olgu serileri bulunmaktadır.

Yüksek tibial osteotomi geçirmiş hastalarda görülebilen komplikasyonlar, sıklıkla cerrahi sırasında karşılaşılan güçlüklerden kaynaklanmaktadır. Proksimal tibianın subperiosteal açılımı ve ekstansör mekanizmanın eversiyonu aşamasında yumuşak dokuların fibrotik olması nedeni ile, zorluk yaşanabilir. Bazı yazarlar, hem açıımı kolaylaştırmak hem de patellar dizilim bozukluğunun (maltracking) minimuma indirilmesi için, lateral gevşetme işlemini rutin olarak önermektedirler.[19]

Ligamentöz denge ayarlanırken dikkatli olunmalıdır. Literatürde ligamentöz instabilite gelişebildiği rapor edilse de ${ }^{[20]}$, birçok çalışmada bu duruma rastlanılmamıştır. ${ }^{[18,21]}$ Ligamentöz dengenin ayarlanması cerrahi süreyi uzatsa da, cerrahi süre ile enfeksiyon oranı arasında anlamlı bir ilişki gösterilememiştir. ${ }^{[22]}$ Literatürde, yüksek tibial osteotomi sonrası primer TDA uygulanan hastalarda patella bajanın daha sık görüldüğü rapor edilmiştir. Fakat, bu durumun fonksiyonel sonucu olumsuz olarak etkilediği gösterilememiştir. ${ }^{[17]}$

Ekspojurdaki zorluk, istenilen cerrahi tekniğin uygulanmasını zorlaştırır. Tibial komponentin yerleştirilmesi sırasında proksimal tibiadaki metafiz kaybı, tespiti güçleştirebilir. Bu nedenle, revizyon stemleri kullanılması gerekebilir. Fakat, osteotomi sonrası intramedüller kanal yer değiştirmiş olabileceğinden, stemlerin yerleştirilmesinde problem yaşanabileceği önceden düşünülmelidir. ${ }^{[23]}$

Daha önceden, yüksek tibial osteotomi uygulanan ve uygulanmayan hastaların primer diz artroplastisi sonrası enfeksiyon oranları arasında anlamlı fark bulunmamıştır. Ancak, yazarlar implant çıkarılması esnasında geniş disseksiyon gereken durumlarda, aynı seansta primer diz artroplastisi de yapılmasını önermemekte, lateraldeki yara iyileştikten sonra diz protezi uygulanmasını tavsiye etmektedirler. ${ }^{[21]}$

\section{NÖROPATIK ARTROPATI SONRASI KOMPLIKASYONLAR}

Charcot artropatisinin tedavisi tartışmalı bir konudur. Diz eklemi sıklıkla tutulmaktadır. TDA bu hasta grubunda bazı yazarlara göre kontrendike olarak görülse de, günümüzde bir tedavi seçeneği olarak uygulanabilmektedir. Charcot artropatisinde TDA uygulanacak hasta seçimi oldukça önemlidir; çünkü bu hastalarda \%47'ye varan komplikasyon oranları rapor edilmiştir.

Dislokasyon \%7 sıklığında rapor edilen bir komplikasyondur. Parvizi ve ark., Charcot artropatili hastalarda cerrahi esnasında yeterli stabilite elde edilemediğinde, stemli veya kısıtlayıcı tip artroplasti seçeneklerini önermektedirler. ${ }^{[24]}$ Yazarlar, ligamentöz dengenin iyi sağlanmasına ve kemik defektlerinin rekonstrüksiyonuna dikkat çekmektedirler. Özellikle kemik defektleri augmente edildiğinde, stabilitenin daha da artacağı düşünülmektedir. ${ }^{[25]}$ Periprostetik kırık gelişmesi sık görülen bir diğer komplikasyondur. Bu durumun açık 
redüksiyon ve internal tespit ile tedavisi önerilmektedir. Derin ven trombozunun, bu hasta grubunda primer osteoartritli hastalara göre daha sık görüldügüü rapor edilmiştir. ${ }^{[26]}$ Daha nadir fakat ciddi komplikasyon olarak, cerrahi sırasında patellar tendon yırtığı ve mediyal bağ hasarı görülebilir. Deforme olan eklem açılımı sırasında bu komplikasyonlara dikkat edilmelidir. ${ }^{[27]}$

Charcot artropatisine bağlı uygulanan primer diz artroplastinin fonksiyonel sonuçları daha düşük olsa da, hastaların ağrı durumlarında anlamlı derecede iyileşme görülmektedir. Bu hasta grubunda ligamentöz dengenin ve kemik diziliminin sağlanmasıyla, kemik defektlerinin augmentasyonuyla ve gerek duyulduğunda hareket kısıtlayıcı (constrained) implantların kullanılmasıyla; literatürde bahsedilen yüksek komplikasyon oranları azaltılabilir. ${ }^{[24]}$

\section{SONUÇ}

Günümüzde, yaşam süresinin uzaması ve tıbbi tedavilerin ilerlemesine bağlı olarak, osteoartrit dışı nedenlerden uygulanan primer TDA sayısı artış göstermektedir. Bu endikasyonlar arasında; sıklıkla romatolojik hastalıklar, hemofilik artropati, yüksek tibial osteotomi sonrası görülen osteoartrit ve nöropatik artritler sayılabilir. Bu hastaların cerrahileri planlanırken, hasta bir bütün olarak düşünülmelidir. Medikal durumları, kullandıkları ilaçlar ve kemik kaliteleri iyi değerlendirilmelidir. Sık görülen komplikasyonların farkında olunması ve gerekli önlemler alınması, komplikasyon oranlarını azaltabilir.

\section{KAYNAKLAR}

1. Dindo D, Demartines $N$, Clavien PA. Classification of Surgical Complications: A New Proposal With Evaluation in a Cohort of 6336 Patients and Results of a Survey. Ann Surg 2004;240(2):205-13. Crossref

2. Chmell MJ, Scott RD. Total knee arthroplasty in patients with rheumatoid arthritis. An overview. Clin Orthop Relat Res 1999;366:54-60. Crossref

3. Cancienne JM, Werner BC, Browne JA. Complications of Primary Total Knee Arthroplasty Among Patients With Rheumatoid Arthritis, Psoriatic Arthritis, Ankylosing Spondylitis, and Osteoarthritis. J Am Acad Orthop Surg 2016;24(8):567-74. Crossref

4. Kurdi AJ, Voss BA, Tzeng TH, Scaife SL, El-Othmani MM, Saleh KJ. Rheumatoid Arthritis vs Osteoarthritis: Comparison of Demographics and Trends of Joint Replacement Data from the Nationwide Inpatient Sample. Am J Orthop (Belle Mead NJ) 2018;47(7). Crossref

5. Scherrer $C B$, Mannion AF, Kyburz D, Vogt M, Kramers de Quervain IA. Infection risk after orthopedic surgery in patients with inflammatory rheumatic diseases treated with immunosuppressive drugs. Arthritis Care Res (Hoboken) 2013;65(12):2032-40. Crossref

6. Howe CR, Gardner GC, NJ Kadel. Perioperative medication management for the patient with rheumatoid arthritis. J Am Acad Orthop Surg 2006;14(9):544-51. Crossref

7. Nikolaisen C, Figenschau Y, Nossent JC. Anemia in early rheumatoid arthritis is associated with interleukin 6-mediated bone marrow suppression, but has no effect on disease course or mortality. J Rheumatol 2008;35(3):380-6.
8. Bogoch ER, Moran EL. Bone abnormalities in the surgical treatment of patients with rheumatoid arthritis. Clin Orthop Relat Res 1999;366:8-21. Crossref

9. Niki $Y$, Matsumoto $H$, Hakozaki A, Mochizuki T, Momohara S. Rheumatoid arthritis: a risk factor for deep venous thrombosis after total knee arthroplasty? Comparative study with osteoarthritis. J Orthop Sci 2010;15(1):57-63. Crossref

10. Singh JA, Lewallen DG. Better functional and similar pain outcomes in osteoarthritis compared to rheumatoid arthritis after primary total knee arthroplasty: a cohort study. Arthritis Care Res (Hoboken) 2013;65(12):1936-41. Crossref

11. Goodman SM, Johnson B, Zhang M, Huang WT, Zhu R, Figgie M, Alexiades M, Mandl LA. Patients with Rheumatoid Arthritis have Similar Excellent Outcomes after Total Knee Replacement Compared with Patients with Osteoarthritis. J Rheumatol 2016;43(1):46-53. Crossref

12. Goddard NJ, Mann HA, Lee CA. Total knee replacement in patients with end-stage haemophilic arthropathy: 25-year results. J Bone Joint Surg Br 2010;92-B(8):1085-9. Crossref

13. Wiedel J, Stabler S, Geraghty S, Funk S. Joint Replacement Surgery in Hemophilia. World Fed Hemophilia 2010;50:1-17.

14. Atilla B, Caglar O, Pekmezci M, BuyukasikY, Tokgozoglu AM, Alpaslan M.. Pre-operative flexion contracture determines the functional outcome of haemophilic arthropathy treated with total knee arthroplasty. Haemophilia 2012;18(3):358-63. Crossref

15. Dargaud Y, Meunier S, Negrier C. Haemophilia and thrombophilia: an unexpected association! Haemophilia 2004;10(4):319-26. Crossref

16. Cancienne JM, Werner BC, Browne JA. Complications After TKA in Patients With Hemophilia or Von Willebrand's Disease. J Arthroplasty 2015;30(12):2285-9. Crossref

17. Meding JB, Keating EM, Ritter MA, Faris PM.. Total Knee Arthroplasty After High Tibial Osteotomy: A Comparison Study in Patients Who Had Bilateral Total Knee Replacement. J Bone Joint Surg Am 2000;82(9):1252-9. Crossref

18. Nizard RS, Cardinne L, Bizot P, Witvoet J. Total knee replacement after failed tibial osteotomy: results of a matchedpair study. J Arthroplasty 1998;13(8):847-53. Crossref

19. Windsor RE, Insall JN, Vince KG. Technical considerations of total knee arthroplasty after proximal tibial osteotomy. J Bone Joint Surg Am 1988;70(4):547-55. Crossref

20. Staeheli JW, Cass JR, Morrey BF. Condylar total knee arthroplasty after failed proximal tibial osteotomy. J Bone Joint Surg Am 1987;69(1):28-31. Crossref

21. Saleh K, Olson M, Resig S, Bershadsky B, Kuskowski M, Gioe $\mathrm{T}$, Robinson H, Schmidt R, McElfresh E. Predictors of wound infection in hip and knee joint replacement: results from a 20 year surveillance program. J Orthop Res 2002;20(3):506-15. Crossref

22. van Raaij TM, Reijman M, Furlan AD, Verhaar JA. Total knee arthroplasty after high tibial osteotomy. A systematic review. BMC Musculoskelet Disord 2009;10:88. Crossref

23. Parvizi J, Marrs J, Morrey BF. Total knee arthroplasty for neuropathic (Charcot) joints. Clin Orthop Relat Res 2003;416:145-50. Crossref

24. Patel A, Saini AK, Edmonds ME, Kavarthapu V. Diabetic Neuropathic Arthropathy of the Knee: Two Case Reports and a Review of the Literature. Case Rep Orthop 2018;2018:9301496. Crossref

25. Babazadeh S, Stoney JD, Lim K, Choong PFM. Arthroplasty of a Charcot knee. Orthop Rev (Pavia) 2010;2(2):e17. Crossref

26. Kim YH, KimJS, Oh SW. Total knee arthroplasty in neuropathic arthropathy. J Bone Joint Surg Br 2002;84(2):216-9. Crossref 